\title{
Electronic versus Paper-based data collection for conducting health-care research: A cost- minimization analysis
}

Sirshendu Chaudhuri ( $\nabla$ sirshendusisu@gmail.com )

ICMR-National Institute of Epidemiology

Bhavani Shankara Bagepally

ICMR-National Institute of Epidemiology https://orcid.org/0000-0003-0856-767X

Ditipriya Bhar

ICMR-National Institute of Epidemiology

S. Uday Kumar

Apollo Institute of Medical College and Research, Chittoor

\section{Research Article}

Keywords: Cost comparison, Cost-estimation, Cost-minimization Analysis, Data collection, Paper-based data collection (PDC)

Posted Date: January 9th, 2021

DOI: https://doi.org/10.21203/rs.3.rs-142628/v1

License: (9) This work is licensed under a Creative Commons Attribution 4.0 International License. Read Full License 


\section{Title page}

(i) Type of manuscript: Original article

(ii) Title: "Electronic versus Paper-based data collection for conducting healthcare research: A cost-minimization analysis"

(iii) Short title: Electronic versus paper-based data collection

(iv) Word counts for abstract: 249

(v) Key words in alphabetical order: Cost comparison, Cost-estimation, Costminimization Analysis, Data collection, Paper-based data collection (PDC)

(vi) Key words in alphabetical order:

(vii) Word count for full text (excluding tables and figures): 1871

(viii) Number of Tables: 3

(ix) Number of Figures: 6

(x) Source of financial support in the form of grants: Nil

(xi) Acknowledgement: Nil

\section{Registration number in case of Clinical Trials: Not applicable}

\section{Authors details:}

\begin{tabular}{|l|l|l|l|}
\hline $\begin{array}{l}\text { Sequenc } \\
\text { e }\end{array}$ & $\begin{array}{l}\text { Authors' name and } \\
\text { Affiliation }\end{array}$ & Email ID & Specific Contribution \\
\hline 1 & $\begin{array}{l}\text { Sirshendu Chaudhuri, } \\
\text { ICMR- National } \\
\text { Institute of } \\
\text { Epidemiology, } \\
\text { Chennai, India }\end{array}$ & sirshendusisu@ gmail.com & $\begin{array}{l}\text { Study conception and design, } \\
\text { Acquisition of data, Analysis } \\
\text { and interpretation of data, } \\
\text { Drafting of manuscript }\end{array}$ \\
\hline 2 & $\begin{array}{l}\text { Bhavani Shankara } \\
\text { Bagepally, ICMR- } \\
\text { National Institute of } \\
\text { Epidemiology, } \\
\text { Chennai, India }\end{array}$ & bshankara@ gmail.com & $\begin{array}{l}\text { Acquisition of data, Analysis } \\
\text { and interpretation of data, } \\
\text { Drafting of manuscript, } \\
\text { Critical revision }\end{array}$ \\
\hline
\end{tabular}




\begin{tabular}{|l|l|l|l|}
\hline 3 & $\begin{array}{l}\text { Ditipriya Bhar, } \\
\text { ICMR- National } \\
\text { Institute of } \\
\text { Epidemiology, } \\
\text { Chennai, India }\end{array}$ & ditipriya.bhar@gmail.com & $\begin{array}{l}\text { Analysis and interpretation of } \\
\text { data, Critical revision }\end{array}$ \\
\hline 4 & $\begin{array}{l}\text { S. Uday Kumar } \\
\text { Reddy, Apollo } \\
\text { Institute of Medical } \\
\text { College and Research, } \\
\text { Chittoor, India }\end{array}$ & $\underline{\text { @ gmail.com }}$ & $\begin{array}{l}\text { Acquisition of data, Critical } \\
\text { revision }\end{array}$ \\
\hline
\end{tabular}

Conflict of interest: Nil

\title{
Corresponding Author:
}

Dr. Sirshendu Chaudhuri,

Consultant I (Online courses Division),

ICMR-National Institute of Epidemiology, Chennai.

Contact- 8778183569

E-main ID: sirshendu@nieicmr.org.in / sirshendusisu@gmail.com

Title: Electronic versus Paper-based data collection for conducting health-care research: A cost-minimization analysis

\begin{abstract}
:
Introduction- Containing expenditure and efficient resource use is essential to limit the increasing costs of health research. Electronic data collection (EDC) is thought to reduce the costs compared to paper-based data collection (PDC). Economic evidence in this area is scanty,
\end{abstract}


especially in low and middle-income countries. Hence, an economic evaluation was conducted to compare the cost between EDC and PDC

Methods- A cost-minimization study was conducted to compare between EDC and PDC from the institutional perspective for the year 2018, based on a community-based survey. Step-down cost accounting was adopted with a bottom-up approach for cost estimation. Total and unit costs were estimated with the base case comparison between EDC and PDC while using SPSS software (e-SPSS and p-SPSS, respectively). We conducted scenario analyses based on usage of different software, R and STATA for both EDC and PDC (e-R, p-R, e-STATA and pSTATA respectively). One-way and probabilistic sensitivity analysis (PSA) was performed to examine the robustness of the observed results.

Results- In the base-case analysis, total costs of EDC and PDC were ₹72,617 (\$1060.9) and 87,717 (\$1281.5) respectively- with estimated cost minimization of ₹ 15,100 (\$220.6). In other scenarios, the estimated cost minimization for e-R, e-STATA, p-R, p-STATA were ₹ -274 (\$4.0), 98 (\$1.4), $14826(\$ 216.6)$, and 15,002 (\$219.2) respectively when compared to EDCSPSS. On one-way and PSA, the results of the cost-minimization analysis were robust.

\section{Conclusion-}

The EDC minimizes institutional cost for conducting health research. This finding will help researchers in planning for the budget for their research to use the resources efficiently

\section{Keywords:}

Cost comparison, Cost-estimation, Cost-minimization Analysis, Data collection, Paper-based data collection (PDC)

\section{Introduction}

A sustainable health research environment requires an integrated contribution from individual, institutional, national and international solidarity. A major proportion of health research costs in low-and middle-income countries (LMICs) are contributed by the donor funding and grants. (1) However, available funding resources are much limited in comparison of what is required. (2) Therefore, the cost of research can be well managed by systematic planning and implementation as well as efficient use of resources during data collection, management and analysis. (2)

Paper-based data collection (PDC) using paper case report forms (CRFs) are the conventional method of data collection in health research. Additionally, PDC can be a laborious and error- 
prone process. (3) With the innovation of information technology, an increasing trend of use of electronic data collection (EDC) has been observed in many regions of the World. (4) Evidence suggests that in LMIC settings, EDC may serve as an effective platform to collect and transfer large quantities of data successfully. (5) In India, although systematic evidence on the use of EDC is lacking, the Indian government's policy on the use of m-health for service delivery by health workers is an indication of an increasing trend in the application of EDC. (6) With the advent of Health Information Technology in India, there is an increasing trend of EDC by small to extensive scale surveys and trials than traditional PDC in researches. (7-9) Current literature from different country settings has identified various advantages of EDC when compared to PDC. It is reported that EDC ensures increased accuracy, greater efficiency of data capture, better quality control of data management, rapid analysis of data, as well as a reduction in the cost of data collection. $(3,4,10-12)$ However, the cost of EDC and PDC can be contextually different and study-specific. (4) Despite the rapid increase of EDC in India, there is hardly any study examining the cost difference between the two methods. Hence, based on a cross-sectional survey, an economic evaluation from the institute's perspective was conducted to examine the cost difference between the costs of traditional PDC and EDC.

\section{Methods}

An economic evaluation was conducted by a cost-minimization analysis approach to examine the costs incurred in different modes of data collection and methods applied while conducting health research. This economic evaluation is based on a single community-based survey (13) in the state of Andhra Pradesh, India. This survey was conducted in a rural area of Andhra Pradesh from a private medical college. The survey was conducted from May to September 2018. Data for this study was collected electronically through an android device using KoBoCollect open data kit (14)

Retrospectively costing was assigned to this survey. (13) For costing, a step-down cost accounting was adopted with a bottom-up approach. All the costs were estimated from an institutional perspective. We identified different cost centres and cost components within each of the cost centres for various activities/processes involved in the study. Then we imparted costs for each of the components. All the costs were estimated in Indian Rupee (₹) for the year 2018 (Also converted into USD; conversion rate: $1 \$=68.45 ₹$ as on 1 st July 2018). As the study was of a short period (less than one year), we have not discounted costs.

Cost minimization is the primary outcome of this study. Data collection for the original survey was done electronically, and analysis was done using the Statistical Package for Social 
Sciences Software (SPSS). Similarly, we have imparted costs for all the relevant cost components for PDC, with a fixed study sample size, the same as that of EDC. Thus, we estimated costs of the survey (p-SPSS) assuming that PDC would have been done instead of EDC in relevant cost centres. Then the cost minimization was estimated as the difference in total costs between EDC and PDC mode of data collection.

Then for different scenarios of conducting the same study using different data analysis software was considered. For scenarios, we estimated the costs of the survey if other software like 'R' and 'STATA' would have been used for data analysis for both EDC and PDC approaches. These costs were termed as e-R and e-STATA when EDC was done, and data analysis software were R and STATA, respectively. Similarly, p-R and p-STATA, when PDC was done with analysis using R and STATA, respectively. To examine the uncertainty of results, a one-way sensitivity analysis was conducted by lowering or increasing the individual cost components by $25 \%$. Also, probabilistic sensitivity analysis (PSA) was conducted by simulating the various components of the cost data using a gamma distribution. Based on the assumption that, if the same survey was conducted in low, medium, and high-cost settings, all the respective cost components were documented (supplementary table-1). For example, the cost of a medical college can be situated in a rural setting (Low-cost setting), small towns and cities (medium cost setting) or in metropolitan cities (High-cost setting) where the costs of same items can vary. Using these estimates from three different settings, the measures of dispersion were calculated and used as input while conducting the PSA. All the analyses were performed in Microsoft Excel 2019.

Ethical compliance- The institutional ethics committee clearance has been obtained to conduct the study.

\section{Results}

The primary study (13) was conducted with a sample size of 102 subjects. The steps of the survey were broadly divided into three phases- preparation, data collection, and data analysis and storage (Figure 1).

All identified cost centres and its component costs for both EDC and PDC mode of data collection were tabulated in Table 1 . The costs of the preparatory phase and the data collection phase were similar for both EDC and PDC, with minimal variation between the two. A significant difference in costs between EDC and PDC was noticed in the costs related to data entry and CRF storage section. (Table 1) 
The estimated total costs of EDC-SPSS and PDC-SPSS were ₹ 72,617 and ₹ 87,717 respectively- with estimated cost minimization of ₹ $-15,100$ (Table 2). The data analysis and storage section of cost centres contributed ₹ $14,154(93.7 \%)$ of total cost minimization. In scenario's analysis, estimated cost minimization for EDC-R, EDC-STATA, PDC-R, PDCSTATA were ₹-274, ₹-98, ₹14826 and ₹15,002 respectively when compared to EDC-SPSS. In the one-way sensitivity analysis, the cost minimization between EDC-SPSS and PDC-SPSS was robust with maximum variation was only $<8 \%$ even with a $25 \%$ change in the individual component costs. The most sensitive cost inputs were transportation-related vehicular costs for data collection, the salary of the researcher and the costs of data analysis. (Figure 2). The oneway sensitivity analysis results of all the scenarios were robust with minimal deviation from that of observed base case results (Supplementary Figures S1-S3).

In PSA (Figure 3), results were robust as the PSA mean cost minimization between e-SPSS as compared to p-SPSS were similar to that of base case values (Table 2). Similarly, even in the PSA results in different scenarios were also robust and similar to that cost minimization from the respective base case analysis. Since the costs of software (R and STATA) could not be varied; hence we could not calculate the measures of dispersion and hence both PSA and basecase values were the same. Results of PSA of cost-minimization analysis were shown in a scatter plot with X-axis indicating the total costs of the comparator (p-SPSS) while the Y-axis was indicating the comparators (e-SPSS, e-R, e-STATA, p-R, p-STATA). (Figure 3)

\section{Discussion-}

In this economic evaluation, we have examined the cost minimization that could result from the use of EDC using open-source electronic questionnaires when compared with traditional PDC. We observed that the use of EDC reduces the total cost of health-research by $17 \%$. Higher costs of PDC were mostly (93.7\%) contributed by the cost of data entry and CRF storage. This finding holds good for commonly used software for data analysis.

Estimating the cost-minimization due to EDC is complex and study-specific. One study from South Africa (4) estimated that EDC could reduce the study cost by $50 \%$ over the traditional PDC. Contemporary evidence from other parts of the World also indicates similar findings that the cost minimization can vary between $49 \%$ to $62 \%$. (15) This minimization could be at various levels of the study. In the present study, we found more than $90 \%$ of the estimated cost 
minimization was out of double data entry and the storage of paper case record forms (CRFs). The process involved with tedious data entry, and the necessary data cleaning, reduces the duration of health research and resulting costs involved in it. (16-18) Evidence from LMICs like Ethiopia and Tanzania have shown that the use of EDC reduced the costs by $25 \%$. $(3,19)$ However, the economic evaluation from Ethiopian study (19) considered the cost of electronic devices as single-use, which may cause an over-estimation of cost for EDC.

Although, the cost of the data collection device didn't influence the cost minimization, the choice of device may affect cost minimization. (20) The types of electronic devices may affect the accuracy of the data collection as well in the field due to variation in size, and specification (16). The estimated cost minimization can be affected by the initial expenditure associated with the establishment of a system in an Institution for using EDC methods instead of PDC. $(11,21)$ For example, we used an open-source tool for developing electronic questionnaires in our study. Use of a paid version of a similar tool could have altered the estimate.

The present study highlights various costs incurred to conduct the study from the institutional point of view at various stages of short-duration, community-based survey. Such findings will help in planning for the necessary set-up required by an institution to adopt the EDC approach instead of PDC in health research. The initial planning includes- motivating and training the researchers, technologies needed, financing, maintaining the technology, and solving the ethical concerns associated with handling the data. $(10,22,23)$ Once an electronic data capture system is established in an institution, it can save additional resources like costs, and the researchers can focus better on their research activities. (24)

\section{Limitation-}

In the present study, we could not account for the costs in a few aspects of health research. These include- the cost associated with data cleaning in case of PDC, maintenance charge during storage of data collection. We could not impart such charges as the original study sample size is relatively small and thus finding the present study should be examined cautiously for larger studies. As we use an open-source tool for data collection, the actual cost may vary if an institution could use a paid tool for EDC. The study explored the costs of public health research. Further study observations may not be extended for clinical trials.

\section{Conclusion and recommendation-}

We observed cost-minimization with the use EDC approach as compared to the PDC approach while conducting health research cross-sectional single Centre study. For short studies, we 
strongly recommend using EDC. We also recommend that the research institutions should priorly assess the potential cost of preparation and maintenance related to technologies associated with EDC by incorporating all the stakeholders. Further cost-minimization analysis is warranted for clinical trials and multicentric studies in this area to have a better policy decision by all stakeholders.

\section{Funding: None}

Conflict of interest: None declared

\section{Acknowledgement: Nil}

\section{References}

1. Health WC on M and, Organization WH. Macroeconomics and health : investing in health for economic development : executive summary [Internet]. World Health Organization; 2001 [cited 2020 Mar 26]. Available from: https://apps.who.int/iris/handle/10665/42463

2. WHO | Research costing subject of new ESSENCE document [Internet]. WHO. World Health Organization; [cited 2020 Mar 26]. Available from: https://www.who.int/tdr/news/2012/essence/en/

3. Thriemer K, Ley B, Ame SM, Puri MK, Hashim R, Chang NY, et al. Replacing paper data collection forms with electronic data entry in the field: findings from a study of community-acquired bloodstream infections in Pemba, Zanzibar. BMC Res Notes. 2012 Feb 21;5:113.

4. Dillon DG, Pirie F, Rice S, Pomilla C, Sandhu MS, Motala AA, et al. Open-source electronic data capture system offered increased accuracy and cost-effectiveness compared with paper methods in Africa. J Clin Epidemiol. 2014 Dec;67(12):1358-63. 
5. Patil R, Roy S, Ingole V, Bhattacharjee T, Chaudhary B, Lele P, et al. Profile: Vadu Health and Demographic Surveillance System Pune, India. J Glob Health [Internet]. [cited 2020 Mar 26];9(1). Available from: https://www.ncbi.nlm.nih.gov/pmc/articles/PMC6594669/

6. Bhattacharya S, Kumar A, Kaushal V, Singh A. Applications of m-Health and e-Health in Public Health Sector: The Challenges and Opportunities. Int J Med Public Health. 2018 Aug 7;8(2):56-7.

7. Singh T, Roy P, Jamir L, Gupta S, Kaur N, Jain DK, et al. Assessment of Universal Healthcare Coverage in a District of North India: A Rapid Cross-Sectional Survey Using Tablet Computers. PLOS ONE. 2016 Jun 28;11(6):e0157831.

8. Gupta SK. Paperless clinical trials: Myth or reality? Indian J Pharmacol. 2015 Jul $1 ; 47(4): 349$.

9. Dickinson FM, McCauley M, Madaj B, van den Broek N. Using electronic tablets for data collection for healthcare service and maternal health assessments in low resource settings: lessons learnt. BMC Health Serv Res. 2019 May 27;19(1):336.

10. Rorie DA, Flynn RWV, Grieve K, Doney A, Mackenzie I, MacDonald TM, et al. Electronic case report forms and electronic data capture within clinical trials and pharmacoepidemiology. Br J Clin Pharmacol. 2017;83(9):1880-95.

11. Carvalho JC, Bottenberg P, Declerck D, van Nieuwenhuysen JP, Vanobbergen J, Nyssen M. Validity of an information and communication technology system for data capture in epidemiological studies. Caries Res. 2011;45(3):287-93.

12. Avilés W, Ortega $\mathrm{O}$, Kuan G, Coloma J, Harris E. Integration of Information Technologies in Clinical Studies in Nicaragua. PLOS Med. 2007 Oct 23;4(10):e291.

13. Reddy SUK, Chaudhuri S, Amrin SF, Rabeka G. Nutritional status and dietary intake among unmarried adolescent girls in rural area of Chittoor district: a community based survey. Int J Community Med Public Health. 2019 Aug 27;6(9):4034-42.

14. KoBoToolbox | Data Collection Tools for Challenging Environments [Internet]. KoBoToolbox. [cited 2020 Mar 26]. Available from: https://kobotoolbox.org/ 
15. Pavlović I, Kern T, Miklavčič D. Comparison of paper-based and electronic data collection process in clinical trials: Costs simulation study. Contemp Clin Trials. 2009 Jul;30(4):300-16.

16. Walther B, Hossin S, Townend J, Abernethy N, Parker D, Jeffries D. Comparison of electronic data capture (EDC) with the standard data capture method for clinical trial data. PloS One. 2011;6(9):e25348.

17. Welker JA. Implementation of electronic data capture systems: Barriers and solutions. Contemp Clin Trials. 2007 May 1;28(3):329-36.

18. Brandt CA, Argraves S, Money R, Ananth G, Trocky NM, Nadkarni PM. Informatics tools to improve clinical research study implementation. Contemp Clin Trials. 2006 Apr;27(2):112-22.

19. King JD, Buolamwini J, Cromwell EA, Panfel A, Teferi T, Zerihun M, et al. A Novel Electronic Data Collection System for Large-Scale Surveys of Neglected Tropical Diseases. PLOS ONE. 2013 Sep 16;8(9):e74570.

20. Ventola CL. Mobile Devices and Apps for Health Care Professionals: Uses and Benefits. Pharm Ther. 2014 May;39(5):356-64.

21. Haller G, Haller DM, Courvoisier DS, Lovis C. Handheld vs. laptop computers for electronic data collection in clinical research: a crossover randomized trial. J Am Med Inform Assoc JAMIA. 2009 Oct;16(5):651-9.

22. Pace WD, Staton EW. Electronic Data Collection Options for Practice-Based Research Networks. Ann Fam Med. 2005 May;3(Suppl 1):s21-9.

23. Ayatollahi H, Mirani N, Haghani H. Electronic Health Records: What Are the Most Important Barriers? Perspect Health Inf Manag [Internet]. 2014 Oct 1 [cited 2020 Mar 22];11(Fall). Available from: https://www.ncbi.nlm.nih.gov/pmc/articles/PMC4272437/

24. Mosa ASM, Yoo I, Parker JC. Online Electronic Data Capture and Research Data Repository System for Clinical and Translational Research. Mo Med. 2015;112(1):4652. 
Table 1: Cost centres and its component costs for electronic and paper-based data collection

\begin{tabular}{|c|c|c|c|c|c|c|c|}
\hline \multirow[t]{2}{*}{ Cost centers } & \multirow[t]{2}{*}{ Sources of costs } & \multicolumn{3}{|c|}{ Electronic CRF } & \multicolumn{3}{|c|}{ Pape CRF } \\
\hline & & Unit cost & $\begin{array}{l}\text { No. of } \\
\text { units }\end{array}$ & $\begin{array}{l}\text { Total } \\
\text { costs }\end{array}$ & $\begin{array}{l}\text { Unit } \\
\text { cost }\end{array}$ & $\begin{array}{l}\text { No. of } \\
\text { units }\end{array}$ & $\begin{array}{l}\text { Total } \\
\text { costs }\end{array}$ \\
\hline \multicolumn{8}{|l|}{ A. Preparation } \\
\hline Stationary & Institution & 30.0 & 1 & 30.0 & 30.0 & 1 & 30.0 \\
\hline Computer & Institution & 45.7 & 14 & 639.8 & 45.7 & 14 & 639.8 \\
\hline Internet connection & Institution & 4.4 & 12 & 52.8 & 4.4 & 12 & 52.8 \\
\hline Institutional space used & $\begin{array}{l}\text { Based on average } \\
\text { local rent }\end{array}$ & 66.7 & 12 & 800.4 & 66.7 & 12 & 800.4 \\
\hline Electricity charges & Institution & 10.4 & 9.6 & 99.8 & 10.4 & 9.6 & 99.8 \\
\hline Translation & Local market rate & 250.0 & 1 & 250.0 & 250.0 & 1 & 250.0 \\
\hline $\begin{array}{l}\text { Salary of first } \\
\text { researcher/ hour }\end{array}$ & Institution & 375.0 & 48 & 18000 & 375.0 & 48 & 18000.0 \\
\hline $\begin{array}{l}\text { Salary of second } \\
\text { researcher/ hour }\end{array}$ & $\begin{array}{l}\text { As per ICMR salary } \\
\text { for JRF }\end{array}$ & 129.2 & 24 & $\begin{array}{l}3100 . \\
8\end{array}$ & 129.2 & 24 & 3100.8 \\
\hline $\begin{array}{l}\text { Salary of social worker/ } \\
\text { day }\end{array}$ & Institution & 400.0 & 5 & $\begin{array}{l}2000 . \\
0\end{array}$ & 400.0 & 5 & 2000.0 \\
\hline Transport (Car) & Institution & 10.0 & 200 & $\begin{array}{l}2000 . \\
0\end{array}$ & 10.0 & 200 & 2000.0 \\
\hline $\begin{array}{l}\text { Android device for } \\
\text { piloting/ day }\end{array}$ & Market rate for 2018 & 13.7 & 4 & 54.8 & & & \\
\hline B. Data collection & & & & & & & \\
\hline Printing questionnaire & Institution & - & - & - & 4.5 & 110 & 495.0 \\
\hline Stationary & Institution & & & & 500.0 & 1 & 500.0 \\
\hline $\begin{array}{l}\text { Printing information } \\
\text { sheet and consent form }\end{array}$ & Institution & 7.5 & 110 & 825.0 & 7.5 & 110 & 825.0 \\
\hline
\end{tabular}




\begin{tabular}{|c|c|c|c|c|c|c|c|}
\hline $\begin{array}{l}\text { Salary of second } \\
\text { Researcher/ hour (for } \\
\text { data collection) }\end{array}$ & $\begin{array}{l}\text { As per ICMR salary } \\
\text { for Junior Research } \\
\text { Fellow }\end{array}$ & 129.2 & 192 & $\begin{array}{l}24806 \\
.4\end{array}$ & 129.2 & 110 & 14212.0 \\
\hline Transport charge (Bike) & Institution & 3.0 & 1080 & $\begin{array}{l}3240 . \\
0\end{array}$ & 3.0 & 1080 & 3240.0 \\
\hline $\begin{array}{l}\text { Instrument } 1 \text { - Weighing } \\
\text { scale }\end{array}$ & Institution & 0.9 & 24 & 21.6 & 0.9 & 24 & 21.6 \\
\hline $\begin{array}{l}\text { Instrument 2- Height } \\
\text { measuring scale }\end{array}$ & Institution & 1.6 & 24 & 38.4 & 1.6 & 24 & 38.4 \\
\hline $\begin{array}{l}\text { Instrument } \\
\text { Measuring cups }\end{array}$ & Institution & 25.0 & 1 & 25.0 & 25.0 & 1 & 25.0 \\
\hline $\begin{array}{l}\text { Android device for } \\
\text { electronic } \\
\text { collection }\end{array}$ & Market rate for 2018 & 13.4 & 24 & 321.6 & - & - & - \\
\hline Internet connection & Institution & 4.4 & 24 & 105.6 & - & - & - \\
\hline $\begin{array}{l}\text { C. Data analysis and } \\
\text { storage }\end{array}$ & & & & & & & \\
\hline $\begin{array}{l}\text { Data entry person } \\
\text { (First)/ day }\end{array}$ & $\begin{array}{l}\text { ICMR salary for } \\
\text { data entry operator }\end{array}$ & - & - & - & 533.3 & 4 & 2133.2 \\
\hline $\begin{array}{l}\text { Data entry person } \\
\text { (Second)* }\end{array}$ & $\begin{array}{l}\text { ICMR salary for } \\
\text { data entry operator }\end{array}$ & - & - & - & 533.3 & 4 & 2133.2 \\
\hline $\begin{array}{l}\text { Institutional space used } \\
\text { (For data entry) }\end{array}$ & $\begin{array}{l}\text { Based on average } \\
\text { local rent }\end{array}$ & - & - & - & 66.7 & 8 & 533.6 \\
\hline $\begin{array}{l}\text { Electricity charges } \\
\text { (During data entry) }\end{array}$ & Institution & - & - & - & 10.4 & 7.3 & 75.9 \\
\hline $\begin{array}{l}\text { Data storage in cloud } \\
\text { (KoBotoolbox) }\end{array}$ & KoBoToolbox\# & 0 & 1 & 0 & - & - & 0 \\
\hline $\begin{array}{l}\text { CRF storage (For a } \\
\text { period of } 5 \text { years) }{ }^{\dagger}\end{array}$ & Institution & - & - & 0 & 8612.5 & 1 & 8612.5 \\
\hline $\begin{array}{l}\text { Files to keep printed } \\
\text { CRF }\end{array}$ & Institution & - & - & 0 & 100.0 & 3 & 300.0 \\
\hline $\begin{array}{l}\text { Computer used for data } \\
\text { entry }\end{array}$ & Institution & - & - & 0 & 45.7 & 8 & 365.6 \\
\hline
\end{tabular}




\begin{tabular}{|c|c|c|c|c|c|c|c|}
\hline SPSS cost & Institution & 27.4 & 10 & 274.0 & 27.4 & 10 & 274.0 \\
\hline $\begin{array}{l}\text { Computer used for data } \\
\text { analysis }\end{array}$ & Institution & 45.7 & 10 & 457.0 & 45.7 & 10 & 457.0 \\
\hline $\begin{array}{l}\text { Institutional space used } \\
\text { (For data analysis) }\end{array}$ & & 66.7 & 10 & 667.0 & 66.7 & 10 & 667.0 \\
\hline $\begin{array}{l}\text { Electricity charges for } \\
\text { data analysis }\end{array}$ & Institution & 10.4 & 12.5 & 130.0 & 10.4 & 12.5 & 130.0 \\
\hline $\begin{array}{lll}\text { Salary of first } \\
\text { researcher for data } \\
\text { analysis } & & \end{array}$ & Institution & 375.0 & 40 & $\begin{array}{l}15000 \\
.0\end{array}$ & 375.0 & 40 & 15000.0 \\
\hline
\end{tabular}

*Assuming double data entry

${ }^{\dagger}$ Including cost of cupboard, and maintenance

ICMR-Indian Council of Medical Research, JRF-Junior Research Fellow

Table 2: Total cost of various modes of data collection

\begin{tabular}{|c|c|c|c|c|}
\hline \multirow[t]{2}{*}{ Type of CRF } & \multirow[t]{2}{*}{ Total cost in ₹ $(\$)$} & \multirow[t]{2}{*}{ Cost minimization in $₹(\$)$} & \multicolumn{2}{|c|}{ PSA cost minimization } \\
\hline & & & in ₹ & In $\$$ \\
\hline p-SPSS & $87717(1281.5)$ & - & - & \\
\hline e-SPSS & $72617(1060.9)$ & $15100(220.6)$ & $15895(14910,17132)$ & $232.2(217.8,250.3)$ \\
\hline \multicolumn{5}{|c|}{ Scenario Analysis } \\
\hline $\mathrm{p}-\mathrm{R}$ & $87443(1277.5)$ & $-274(4.0)$ & $-274 *$ & -4 \\
\hline$e-R$ & $72343(1056.9)$ & $15374(224.6)$ & $15895(14910,17132)$ & $232.2(217.8,250.3)$ \\
\hline p-STATA & $87619(1280.0)$ & $98(1.4)$ & $98 *$ & 1.4 \\
\hline e-STATA & $72519(1059.4)$ & $15198(222.0)$ & $15993(15008,17230)$ & $233.6(219.3,251.7)$ \\
\hline
\end{tabular}

(all costs in ₹ for the year 2018)

*Fixed in PSA 
Figure 1: Steps of the primary survey

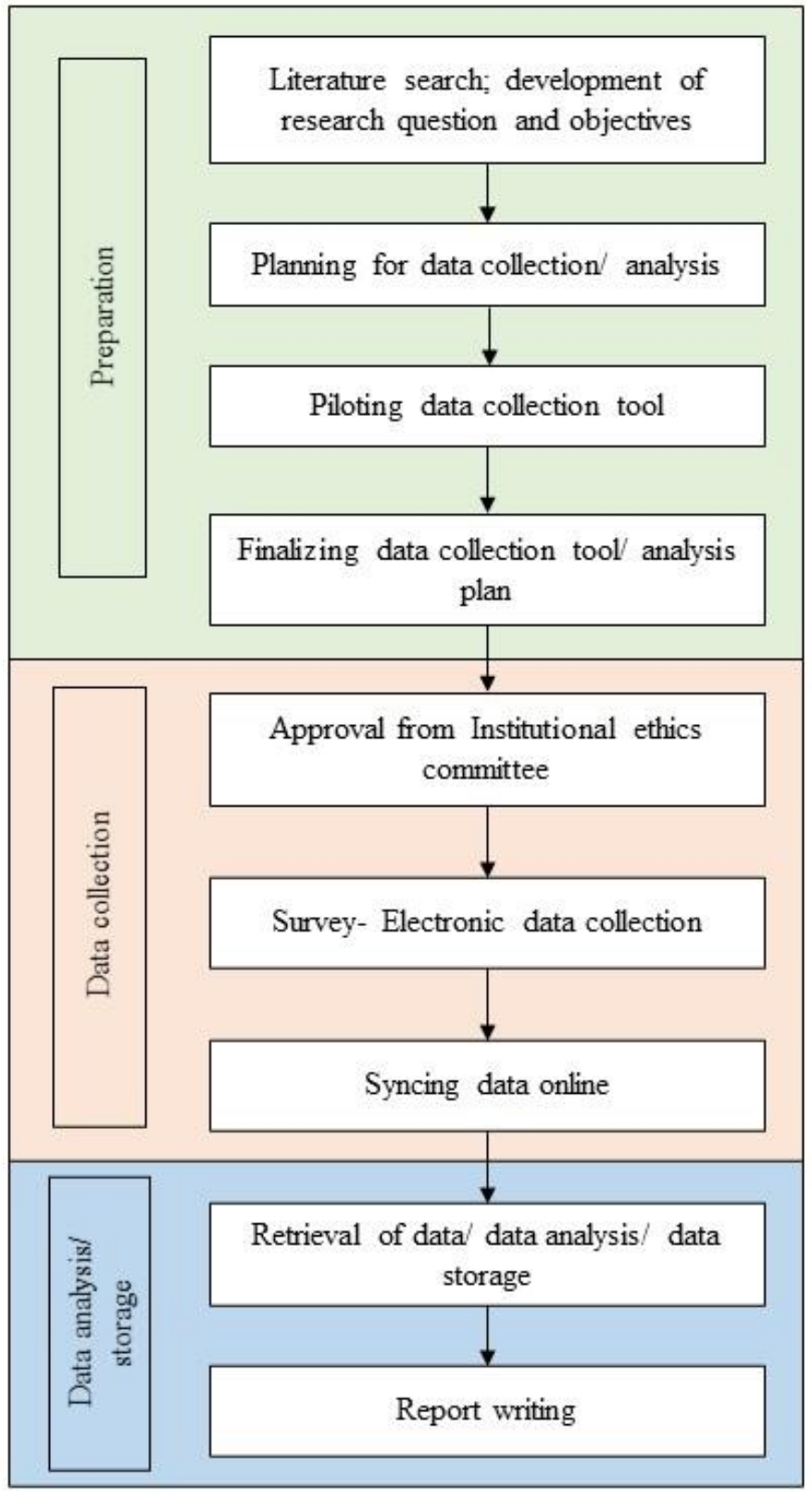

Figure 2: One-way sensitivity analysis for comparison between e-SPSS and p-SPSS 


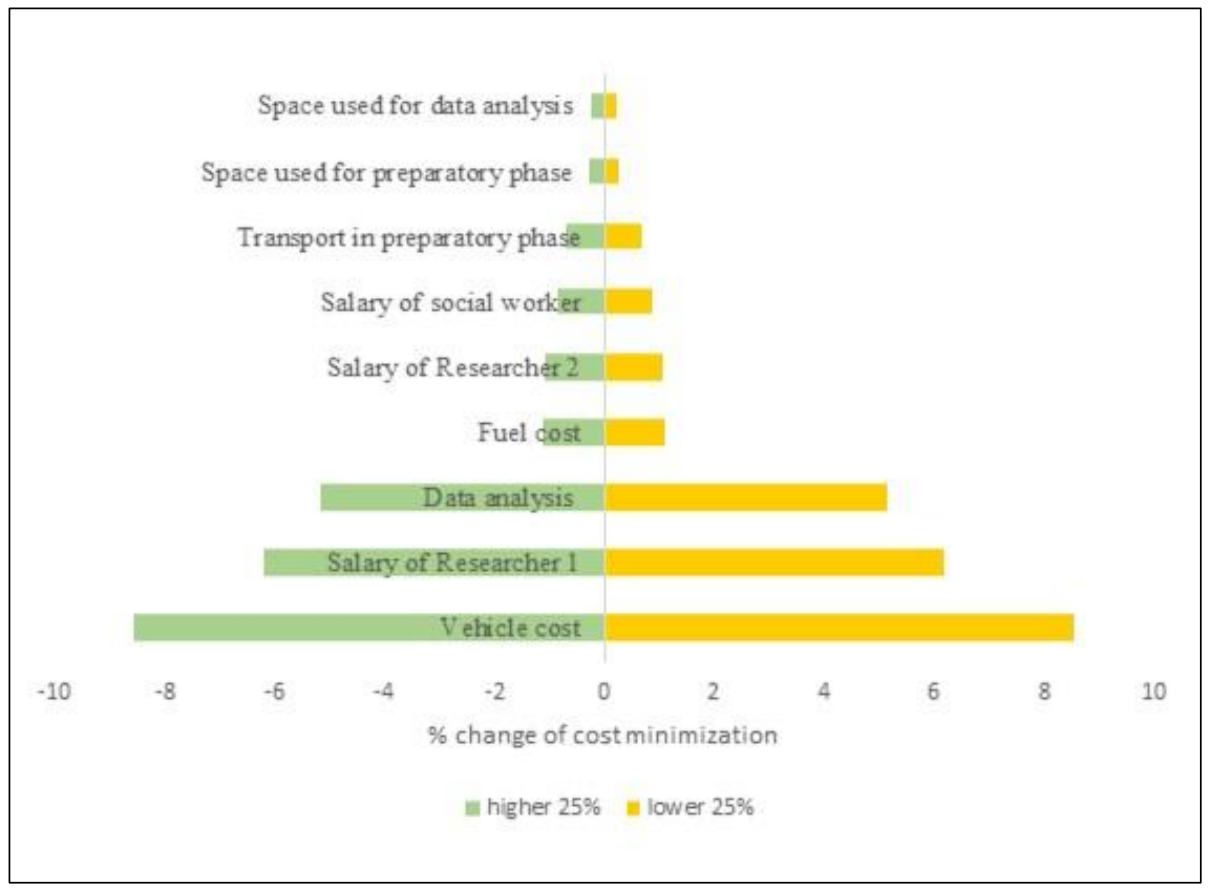

Figure 3: Scatter plot of results PSA between total cost of different mode of data collection with PDC-SPSS

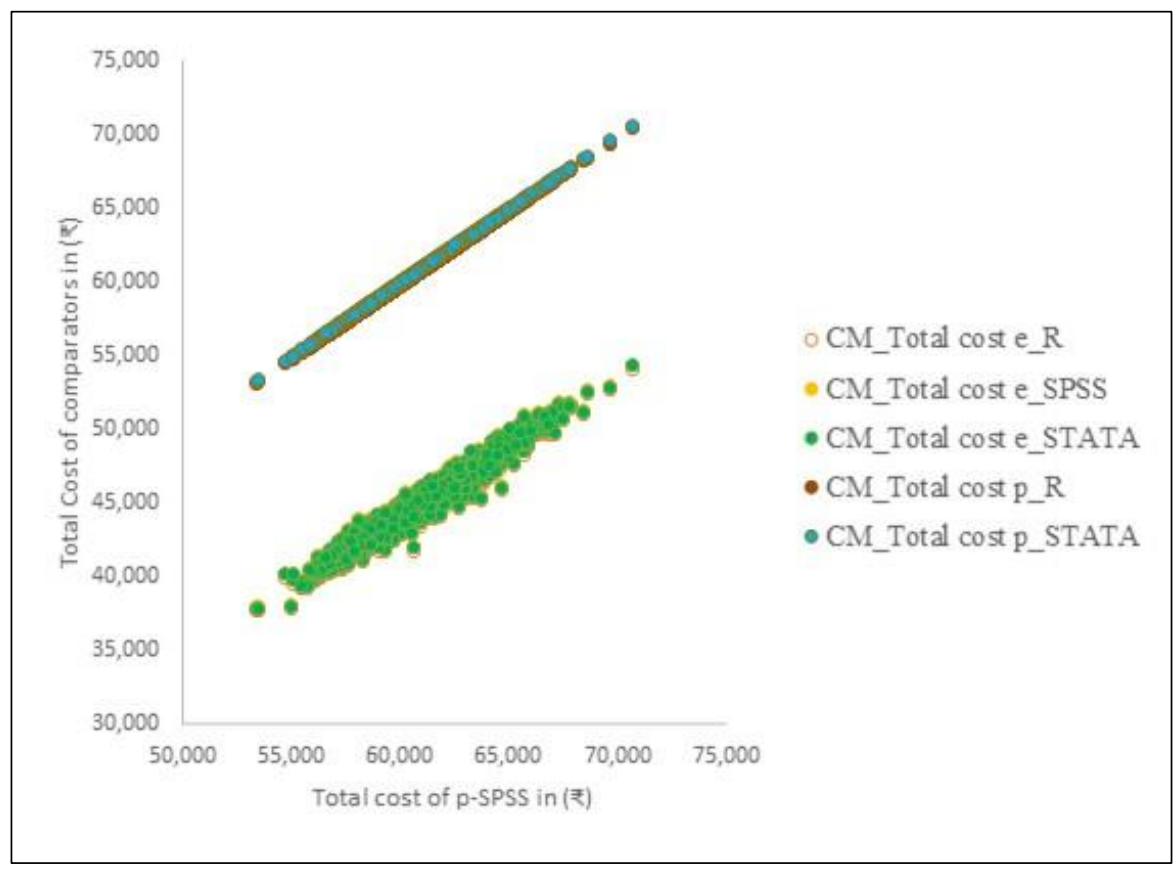

Supplementary table 1: Cost assumption in different setting for probabilistic sensitivity analysis 


\begin{tabular}{|lllll}
\hline Low- & & \\
Actual cost & cost & Medium & High cost & Mean total cost (SD) [Avg. \\
incurred & setting & cost setting & setting & unit cost* No. of units]
\end{tabular}

\section{A. Preparation}

\begin{tabular}{|c|c|c|c|c|c|}
\hline Stationary & 30 & 20 & 40 & 60 & $37.5(17.1)$ \\
\hline Computer & 45.7 & 27.4 & 38.2 & 57.2 & $589.8(175.7)$ \\
\hline Internet connection & 4.4 & 4.4 & 4.4 & 4.4 & 52.8 \\
\hline Institutional space used & 66.7 & 58.3 & 97.2 & 116.7 & $1016.7(324.7)$ \\
\hline Electricity charges & 10.4 & 10.4 & 10.4 & 10.4 & 99.84 \\
\hline Translation & 250 & 200 & 300 & 400 & $287.5(85.4)$ \\
\hline Salary of first researcher/ hour & 375 & 291.6625 & 333.3375 & 416.6625 & $17000.0(2582.0$ \\
\hline \multicolumn{6}{|l|}{ Salary of second researcher/ } \\
\hline hour & 129.2 & 129.2 & 129.2 & 129.2 & 3100.8 \\
\hline Salary of social worker/ day & 400 & 433.3 & 467.7 & 500 & $2251.3(215.9)$ \\
\hline Transport (Car) & 10 & 8 & 11 & 12 & $2050.0(341.6)$ \\
\hline \multicolumn{6}{|l|}{ Android device for piloting/ } \\
\hline day & 13.7 & 11 & 16.4 & 20.5 & $61.6(16.2)$ \\
\hline \multicolumn{6}{|l|}{ B. Data collection } \\
\hline Printing questionnaire & 4.5 & 3 & 6 & 9 & $618.8(281.8)$ \\
\hline Stationary & 500 & 500 & 500 & 500 & 500 \\
\hline \multicolumn{6}{|l|}{ Printing information sheet and } \\
\hline consent form & 7.5 & 5 & 10 & 15 & $1031.3(469.7)$ \\
\hline \multicolumn{6}{|l|}{ Salary of second researcher/ } \\
\hline hour (for data collection) & 129.2 & 129.2 & 129.2 & 129.2 & 24806 \\
\hline Transport charge (Bike) & 3 & 2.5 & 4 & 5 & $3915.0(1200.7)$ \\
\hline Instrument 1- Weighing scale & 0.9 & 0.7 & 1.1 & 1.2 & $23.4(5.3)$ \\
\hline Instrument & & & & & \\
\hline measuring scale & 1.6 & 0.9 & 1.8 & 2.3 & 39.6 13.9) \\
\hline
\end{tabular}


Android device for electronic

data collection

13.7

11

16.4

20.5

$369.6(97.3)$

Internet connection

4.4

4.4

4.4

4.4

105.6

C. Data analysis and storage

Data entry person (First)/ day

533.3

533.3

533.3

533.3

2133.2

Data entry person (Second)*

533.3

533.3

533.3

533.3

2133.2

Institutional space used (For

data entry)

66.7

50

83.3

100

$600(172.1)$

Electricity charges (During data entry)

10.4

10.4

10.4

75.92

Data storage in cloud

(KoBotoolbox)

0

0

0

0

0

CRF storage (For a period of 5

years) $* *$

Files to keep printed CRF

Computer used for data entry

SPSS cost

Computer used for data analysis

Institutional space used (For data analysis)

Electricity charges for data analysis

Salary of first researcher for data analysis
8612.5

8612.5

8612.5

8612.5

8612.5

100

80

125

150

$341.3(91.1)$

45.7

27.4

38.2

57.2

$337.0(100.4)$

27.4

27.4

27.4

27.4

274

45.7

27.4

38.2

57.2

$421.3(125.5)$

66.7

50

83.3

100

$750.0(215.1)$

10.4

10.4

10.4

10.4

130.3 


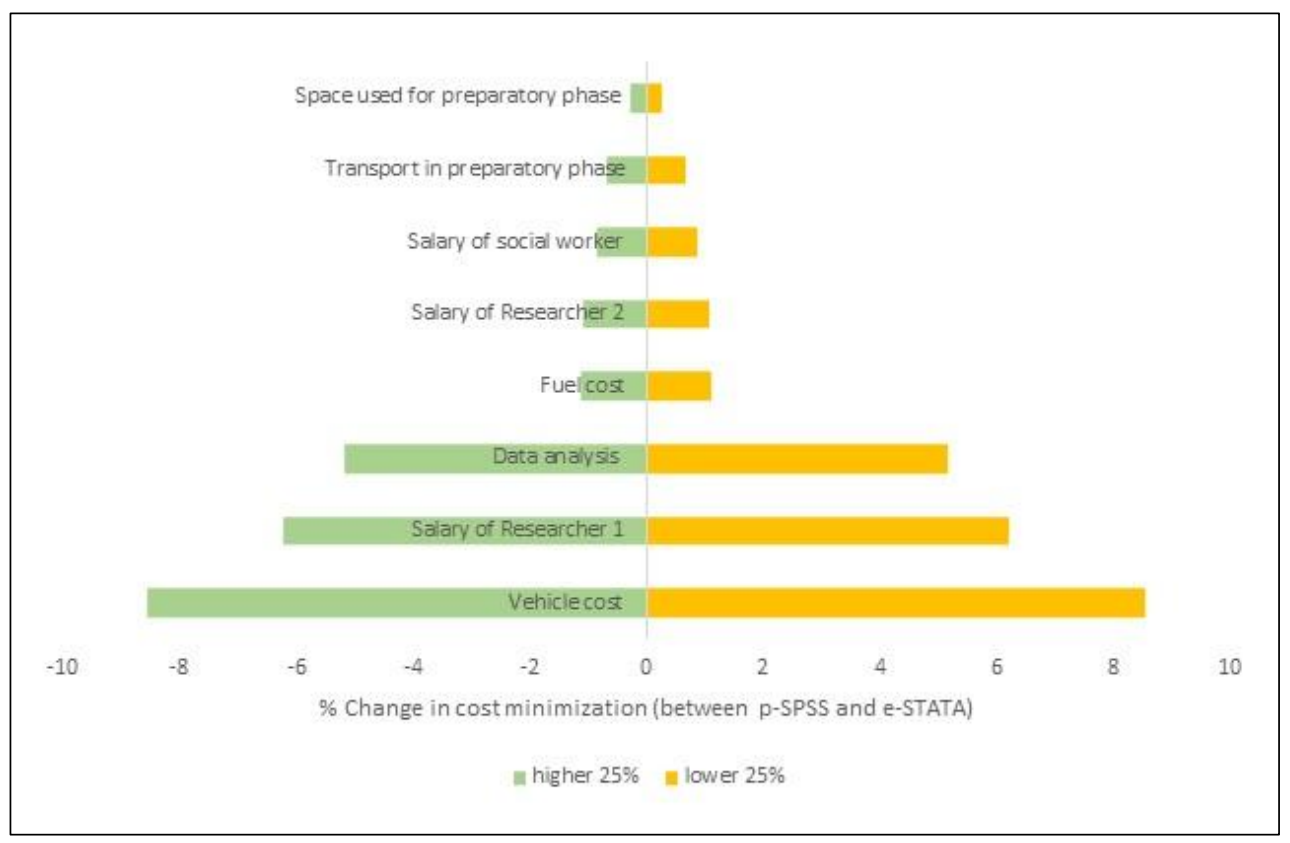

Supplementary Figure S-2: One-way sensitivity analysis for comparison between p-SPSS and pSTATA

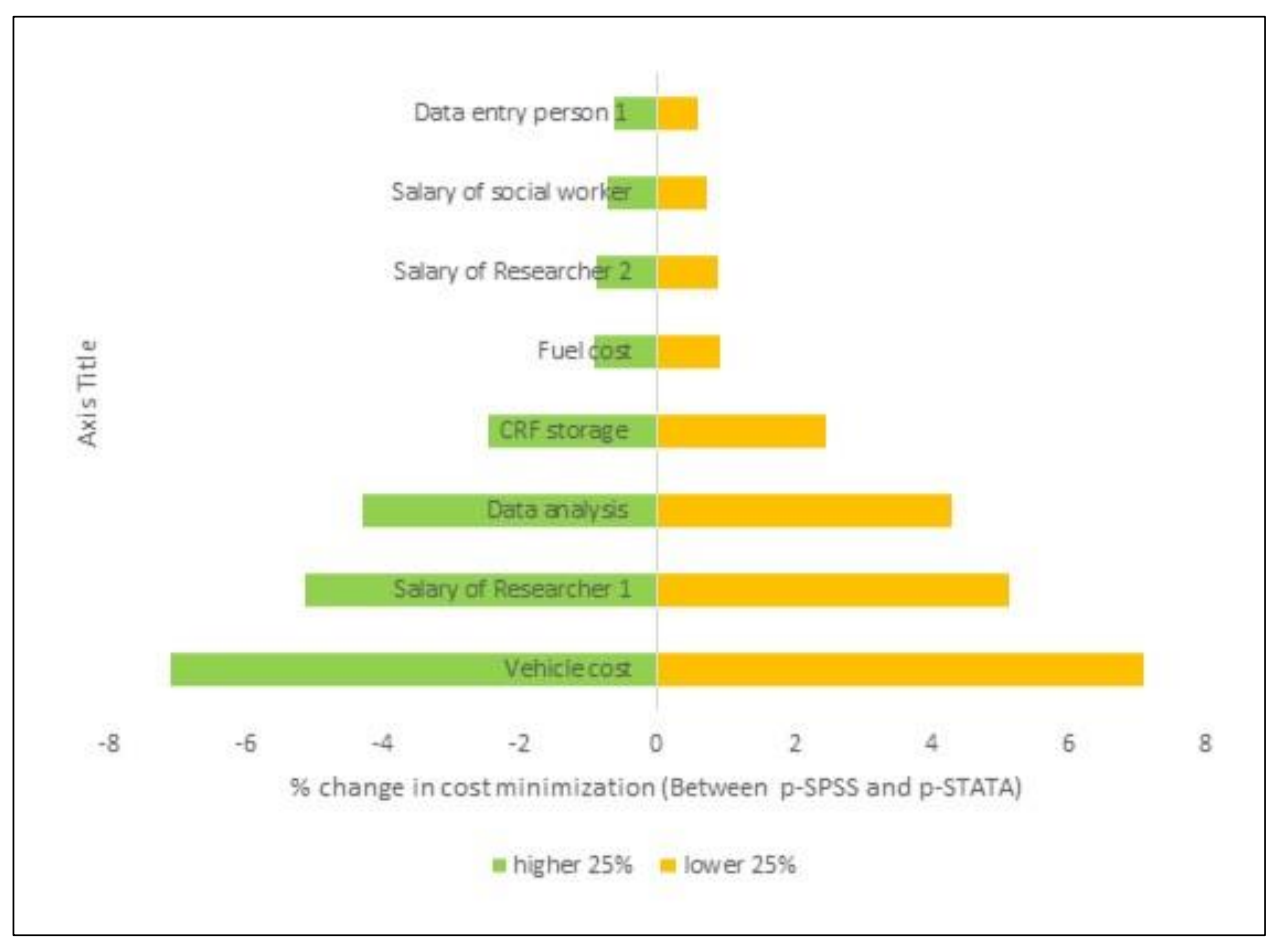

Supplementary Figure S-3: One-way sensitivity analysis for comparison between p-SPSS and p$\mathbf{R}$ 


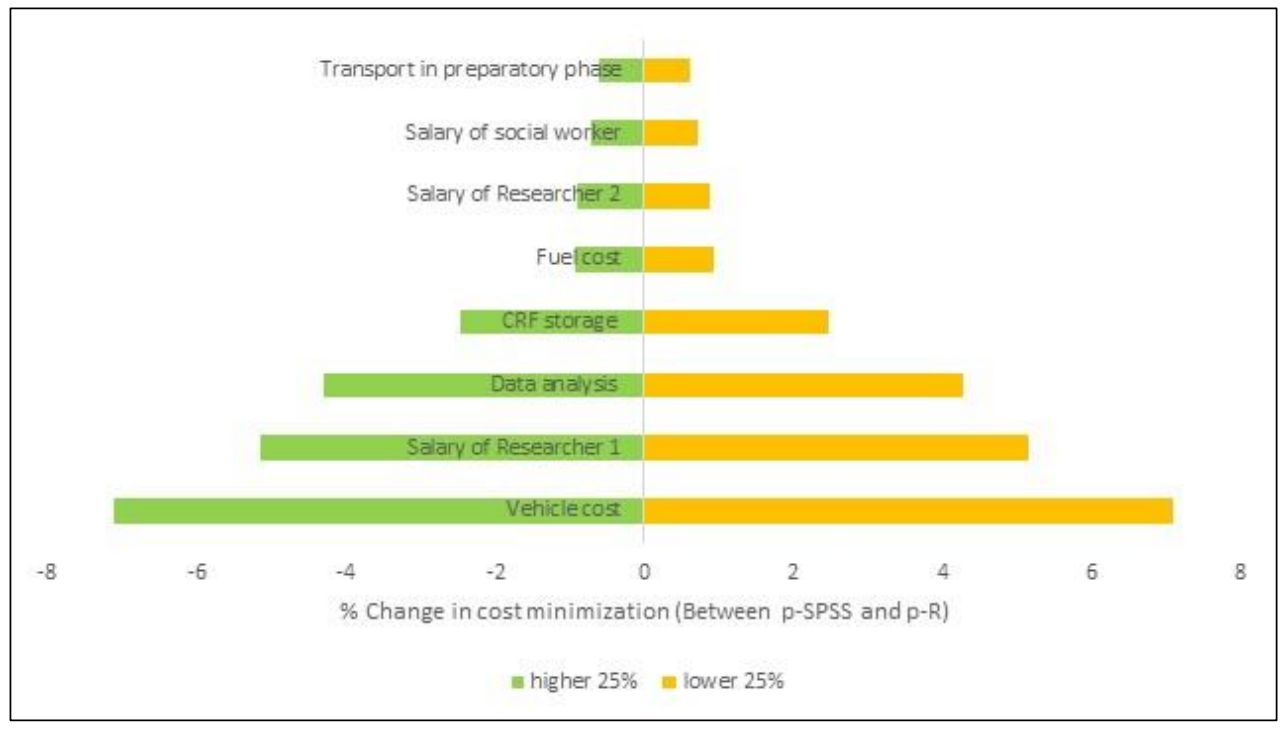


Figures

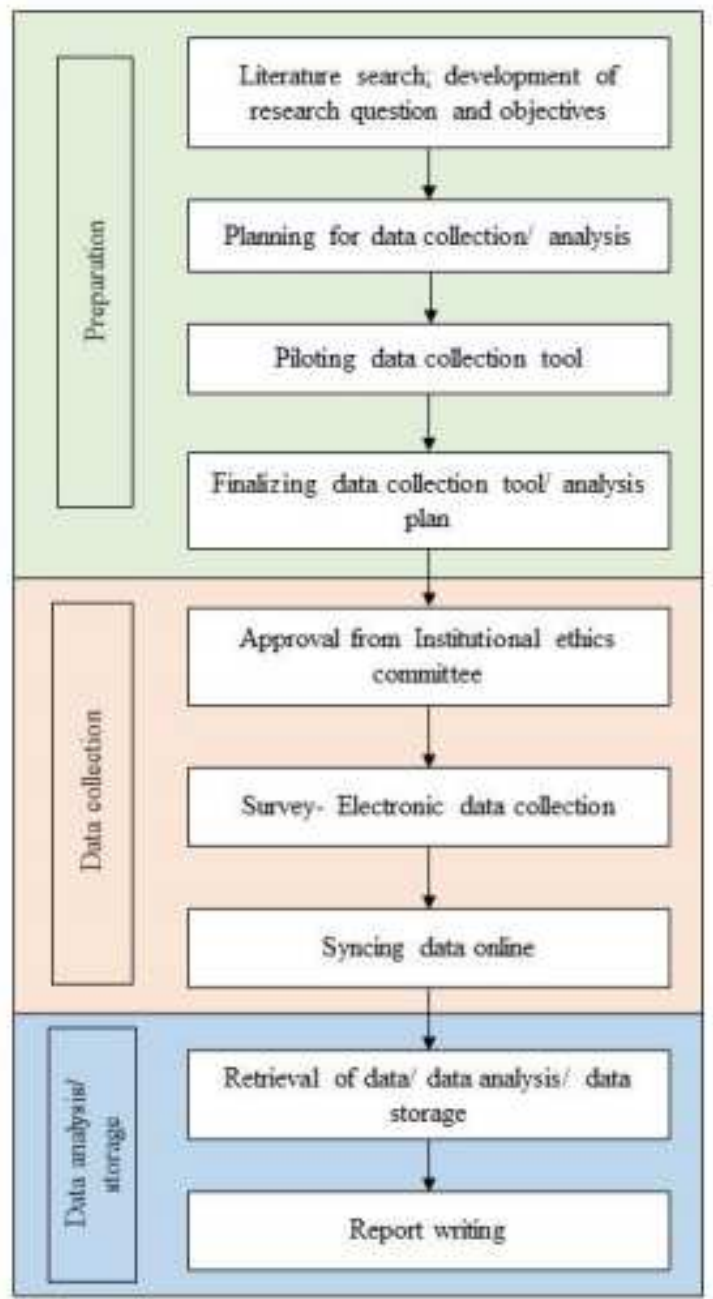

Figure 1

Steps of the primary survey 


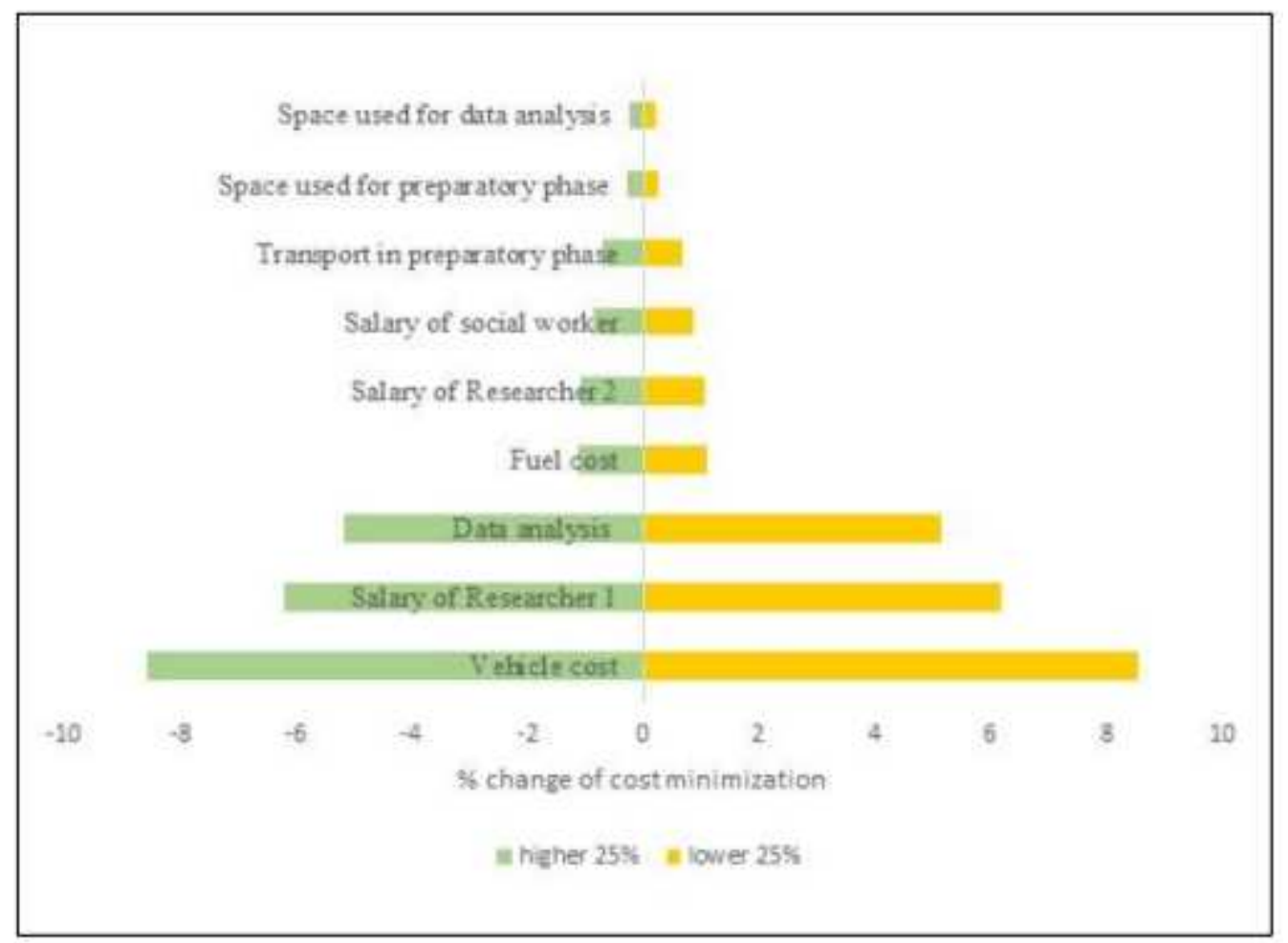

\section{Figure 2}

One-way sensitivity analysis for comparison between e-SPSS and p-SPSS

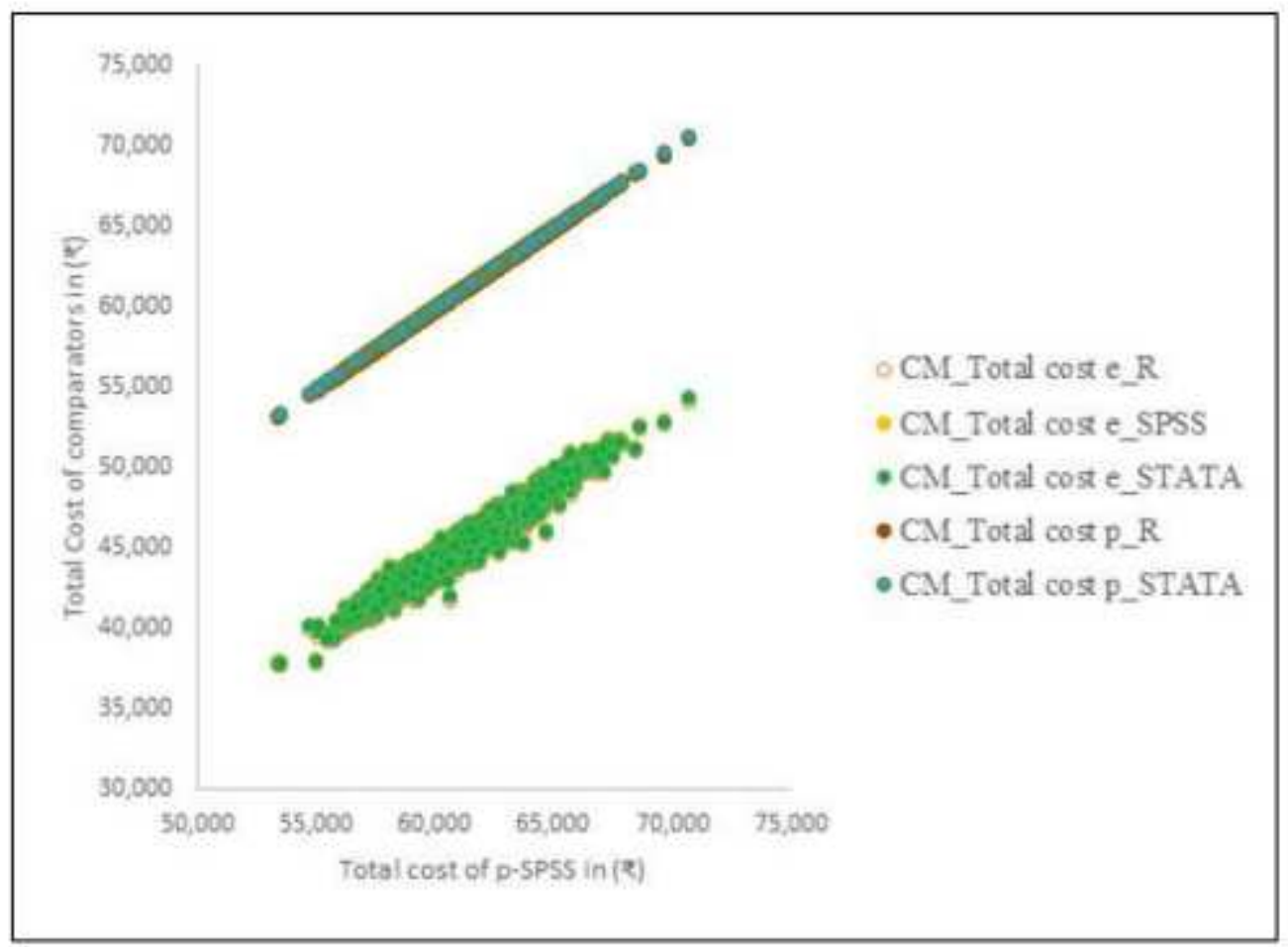

Figure 3

Scatter plot of results PSA between total cost of different mode of data collection with PDC-SPSS 